\title{
Interdependência entre redes e empresas integrantes na evolução de redes interorganizacionais
}

\author{
LEANDER LUIZ KLEIN ${ }^{1}$ \\ Breno Augusto Diniz Pereira 2 \\ ${ }^{1}$ Universidade Federal de SANTA MARia (UFSM) / Departamento de AdMinistração, \\ CAMPUS PalmeIRA das MISSÕES, PALMEIRA das MISSÕES - RS, BRASIL \\ 2 Universidade Federal de SANTA Maria (UFSM) / Departamento de AdMinISTRAÇÃo, SANTA MARIA - RS, BrasiL
}

\begin{abstract}
Resumo
A cooperação entre empresas na forma de redes pode ser considerada um mecanismo para elas conseguirem os recursos que Ihe são faltantes. O fato a ressaltar é que os recursos proporcionados pelas redes podem se tornar únicos ao longo do tempo, e é isso que instiga a realização desse trabalho. O objetivo geral deste é verificar como se desenvolve a relação de interdependência rede-empresa e empresarede ao longo da evolução das redes interorganizacionais. Para tanto, realizou-se uma pesquisa com redes que se encontravam em fases distintas de evolução, sejam elas: Formação, Desenvolvimento e Profissionalização. Para coleta de dados, realizaram-se entrevistas com os presidentes dessas redes e mais dois integrantes de cada uma delas. Dentre os principais resultados dessa pesquisa, ressalta-se o fato de ter sido visualizada uma clara inversão na relação de interdependência investigada. Conclui-se que a dinâmica nos relacionamentos e governança da rede e sua evolução influenciam no delineamento da dependência das empresas com a rede.
\end{abstract}

Palavras-chave: Interdependência. Dependência. Evolução de redes. Recursos.

\section{Interdependence between networks and member firms in the evolution of inter-organizational networks}

\begin{abstract}
Cooperation among firms through networks is a form to obtain a variety of resources. Over time, networks can become an exclusive provider of some resources used by members, leading to dependencys. This study is interested in this phenomenon, and aims to examine how firmnetwork interdependence grows throughout the development of inter-organizational networks. The research was conducted with networks that were in distinct stages of evolution (formation, development, and professionalization). Interviews were carried out with the presidents of the networks and two member firms of each network. The study identified an inversion in the relation of interdependence investigated, where the network is dependent of its members in the first stages of evolution and, as its governance and structure consolidate, members develop a dependency relationship toward the network and the benefits it offers.
\end{abstract}

Keywords: Interdependence. Dependence. Evolution of networks. Resources.

\section{Interdependencia entre redes y empresas integrantes en la evolución de redes interorganizacionales}

\section{Resumen}

La cooperación entre empresas en la forma de redes puede considerarse un mecanismo para que estas puedan obtener los recursos que les faltan. Vale resaltar que los recursos proporcionados por las redes pueden llegar a ser únicos a lo largo del tiempo, y eso es lo que instiga la realización de este trabajo, cuyo objetivo general es verificar cómo se desarrolla la relación de interdependencia red-empresa y empresared a lo largo de la evolución de las redes interorganizacionales. Para ello, se realizó una investigación con redes que se encontraban en fases distintas de evolución, como: Formación, Desarrollo y Profesionalización. Para la recolección de datos, se realizaron entrevistas con los presidentes de esas redes y otros dos integrantes de cada una de ellas. Entre los principales resultados de esta investigación está el hecho de haber percibido una clara inversión en la relación de interdependencia investigada. Se concluye que la dinámica en las relaciones y gobernanza de la red y su evolución influyen en el delineamiento de la dependencia de las empresas con la red.

Palabras clave: Interdependencia. Dependencia. Evolución de redes. Recursos. 


\section{INTRODUÇÃO}

Em geral, o que motiva as organizações a trabalharem juntas é a necessidade de superar a falta de recursos, reduzir as incertezas do mercado e aproveitar as oportunidades que surgem. A esse respeito, as redes podem oferecer uma ampla gama de oportunidades para que as empresas membras participem de atividades que possam complementar suas necessidades de recursos e gerar benefícios e valor organizacional.

A motivação das organizações para se unir e trabalhar juntas em redes é porque elas podem aumentar os recursos, reduzir a incerteza do mercado em que estão inseridas e aproveitar as oportunidades. Nesse sentido, as redes podem fornecer uma gama de atividades que podem complementar as necessidades de recursos empresariais intercambiáveis, fornecer benefícios e valor organizacional aos membros (CENTENARO e LAIMER, 2017; DEBOÇÁ e MARTINS, 2015) e sinergia na rede (HERNANDEZ e SHAVER, 2018).

O fato a ser destacado é que as atividades e os benefícios proporcionados pelas redes podem se tornar únicos e altamente valiosos para alguns membros ao longo dos anos, resultando em diversos resultados sobre diferentes aspectos da função organizacional dessas firmas (MEDCOF, 2001). À medida que as redes interorganizacionais evoluem e se estruturam, essas empresas podem atingir certo nível de profissionalização de suas atividades, proporcionando vantagens exclusivas às empresas associadas, tornando-as dependentes da rede a que pertencem. Segundo a Teoria da Dependência de Recursos, as organizações dependem em parte de seu ambiente e precisam gerenciar recursos externos (PFEFFER e SALANCIK, 1978). Em outras palavras, por mais autônoma que seja uma organização, ela sempre exigirá recursos de terceiros (RIBEIRO e COLAUTO, 2016).

Em contraste, as redes apresentam alguma fragilidade em relação à sua sustentabilidade, ou sobrevivência, especialmente na fase inicial de formação. Sobre este ponto, Klein e Pereira (2016) explicam que quanto maior a dependência da rede em organizações-chave, mais suscetível é a sobrevivência da rede. Isso ocorre porque elas têm apenas alguns membros, e se um deles decide sair, coloca em risco a continuidade das atividades programadas. Além disso, as redes, quando são formalmente constituídas, são organizadas em uma estrutura de governança compartilhada (PROVAN e KENIS, 2007) apoiada por mecanismos sociais. Invariavelmente, esse modo de governança requer participação, engajamento e compromisso de todos os membros da rede para que possam realizar as atividades e ações planejadas. Tal dependência da rede sobre as empresas membras tende a diminuir à medida que a rede cresce e adota estilos de governança mais formais. Fatores sociais e o poder de empresas membros gerados a partir das redes podem motivar essas empresas a responder diferentemente à lógica de dependência de formação e desenvolvimento de redes (XIA, WANG, LIN et al., 2016), e isso direciona ao entendimento dos recursos necessários para a rede (DICKEL, HÖRISCH e RITTER, 2018).

Dadas essas notas, o tema deste artigo é a relação de interdependência entre redes e empresas membras na evolução das redes interorganizacionais, que foi desenvolvido com a finalidade de responder a seguinte questão central: quais são os fatores que influenciam a interdependência entre a rede e as empresas membras na evolução das redes interorganizacionais? Essa questão leva a uma investigação dos aspectos e fatores que afetam a interdependência entre as empresas parceiras e a rede a que pertencem e vice-versa. Assim, o objetivo geral deste estudo é investigar como a relação de interdependência entre redes-empresas e empresas-rede é desenvolvida ao longo da evolução das redes interorganizacionais.

Avaliar a interdependência nos diversos estágios de desenvolvimento da rede atende à compreensão de Popp, Milward, Mackean et al. (2014), que mencionam que uma oportunidade significativa para o progresso de estudos e avaliação de redes reside na concepção e esforços de avaliação conjunta, e métodos alinhados com as etapas de evolução da rede, utilizando as ferramentas de avaliação disponíveis ou adaptação e desenvolvimento de novas. Assim, pretende-se aqui avançar na compreensão da dinâmica colaborativa de negócios através de uma análise da gestão de rede, estrutura e governança e fatores de dependência entre empresas membras da rede e a rede. Como contribuição gerencial, o estudo busca evidenciar as mudanças na relação de interdependência que existe entre empresas membras e a rede, tendo em vista os benefícios gerados pela melhoria de desempenho da rede, pela maior eficácia e especialização das atividades desenvolvidas pela rede, e por uma mudança na estrutura de governança. Acredita-se que mostrar como essa evolução ocorre e o que a suporta pode contribuir para um melhor desenvolvimento e desempenho das redes. 


\section{Fatores influenciadores da dependência da rede}

Dado que a rede é uma nova entidade administrativa a partir de sua constituição formal, formada por empresas independentes que colaboram para um objetivo específico, a sua dependência está relacionada principalmente à fatores relacionais e ao comportamento das empresas associadas. É nesse sentido que a dependência da rede em relação às empresas integrantes foi estudada e explorada.

O primeiro dos fatores estudados foi o comprometimento dos integrantes da rede, que se traduz na expectativa de que o outro ator irá cumprir com as suas obrigações, se comportará de uma maneira previsível, e vai agir e negociar de forma justa, quando a possibilidade de agir de maneira oportunista está presente (ANDERSON e NARUS, 1990). Quando o parceiro é comprometido com o relacionamento, ele irá despender esforços para que este tenha sucesso (CASTRO, BULGACOV e HOFFMANN, 2011).

Andrésen, Lundberg e Roxenhall (2012) definem o comprometimento como a lealdade dos representantes das empresas parceiras à rede como uma unidade específica. Eles mencionam que há uma clara necessidade de comprometimento para realizar processos e atividades da rede e obter resultados positivos. Muitos estudos mencionam e mostram que o comprometimento é um fator chave no estabelecimento de relacionamentos colaborativos e determina as perspectivas de relacionamentos de longo prazo (por exemplo, SEATON, HOLM, BOTTORFF et al., 2018; GUNDLACH, ACHROL e MENTZER, 1995; ROXENHALL, 2011; ANDERSEN e MEDLIN; 2016).

Os diversos tipos de relações entre empresas são tipicamente baseadas no comprometimento que se estabelece através da confiança e da reciprocidade entre os participantes de uma relação (GULATI E SYTCH, 2007). A confiança é outro fator primordial para o início das relações colaborativas e permite que os parceiros centrem a sua atenção e apliquem os seus recursos para promover resultados conjuntos, em vez de perseguir agendas individuais (DIRKS, 1999). Perry, Sengupta e Krapfel (2004) definem a confiança como o grau em que a empresa focal acredita que a empresa parceira é confiável e possui integridade. Para eles, a confiança é a crença de que o parceiro vai honrar as obrigações com as quais se comprometeu, enquanto a integridade é a crença de que o parceiro é honesto e faz o que é certo.

Lewicki e Brinsfield (2011) enfatizam reciprocidade, expectativas ou crenças sobre as intenções do parceiro e a confiança dos outros como essenciais para os arranjos colaborativos. Além disso, Oliveira, Borges, Carvalho et al. (2016) enfatizam que a confiança entre as empresas deve existir e é uma forma de antecipar o comportamento do outro, facilitar o conhecimento de atitudes, trocar informações e transações.

Outro fator que se destaca quando da formação e desenvolvimento de relações interorganizacionais é o consenso quanto aos objetivos e metas a serem alcançadas. Ring e Van de Ven (1994) explicam que a formação de uma visão e metas compartilhadas entre as empresas é essencial para qualquer relação colaborativa. Para Provan e Kenis (2007), o consenso sobre objetivos gerais em nível de rede, na ausência de hierarquia, estimula os membros da rede para se tornarem mais envolvidos e comprometidos com a rede e, portanto, mais propensos a trabalhar juntos. Carvalho, Wegner, Begnis et al. (2018) enfatizam que o desenvolvimento de relações interorganizacionais rentáveis e produtivas requer um alinhamento de objetivos entre os membros da organização.

Na determinação de metas e objetivos, deve haver uma ponderação entre as vontades dos integrantes e as vontades da rede. Para Andrésen, Lundberg e Roxenhall (2012), quando os objetivos da rede estão intimamente associados com os objetivos das organizações membras, os objetivos são mais propensos a ganhar o reforço e aval de todos. Isso gera sentido aos integrantes da rede cooperarem e os estimula a se comprometerem. É necessário enfatizar que Klein e Pereira (2014) relacionam a "falta de congruência e consenso entre os membros em relação aos objetivos da rede" com o fracasso dessa estratégia colaborativa (ou seja, a rede).

Esses fatores foram tomados nesse estudo como essenciais para a continuidade da rede, ainda mais que ela geralmente ela é formada por poucas empresas integrantes. O descontentamento e saída de uma delas, em virtude de divergências quanto aos objetivos e metas ou qualquer outro motivo, pode enfraquecer a rede e dificultar sua evolução.

\section{Fatores influenciadores da dependência das empresas integrantes}

Ao se falar da dependência de uma organização com a rede em que está inserida, deve-se ter em mente os recursos que são necessários para a sobrevivência dessa empresa e que são mediados pela rede. Essa base de recursos necessários a uma organização é explorada aqui como aspectos indispensáveis para sua competitividade, o que gera assim a sua dependência com o ator que os fornece, nesse caso a rede. 
Nesse sentido, formação e o desenvolvimento de relações interorganizacionais são, geralmente, motivados pela busca de eficiência e resultados econômicos maiores se comparados com a atuação de uma empresa individualmente. As redes interorganizacionais são uma alternativa organizacional apropriada principalmente para empresas de pequeno porte. Estas, por sua vez, têm como alternativa competitiva e de êxito o controle de mercado, principalmente, com o uso de preços mais baixos dos produtos e serviços ofertados (PERROW, 1998). Já, por meio da cooperação, as pequenas empresas interagem entre si buscando adquirir poder de barganha e diminuição dos custos de certas atividades que possam ajudá-las a concorrer com outras empresas de maior porte.

Waarden (1992) explica que os ganhos de escala e de poder de barganha proporcionam às empresas parceiras a possibilidade de realização de acordos comerciais em condições exclusivas (antes inalcançáveis) e a ampliação do poder de barganha nas distintas relações econômicas. Isso gera as empresas parceiras integradas em rede uma vantagem competitiva antes inexistente. Jarillo (1988, p. 35) explicita que uma empresa que participa de uma rede "[...] pode incorrer em custos menores porque captura economias de escala (ou qualquer outra fonte de eficiência) de suas firmas associadas, o que outros competidores não conseguem obter isoladamente". No entendimento de Sadowski e Duysters (2008), essas ações conjuntas de colaboração entre empresas também viabilizam a elas a redução dos riscos associados aos negócios, dado o fato de atuarem em conjunto.

Outro fator explorado é a aprendizagem obtida pelos integrantes na rede. Popp, Milward, Mackean et al. (2014) mencionam que a aprendizagem é um processo chave em redes, que está estreitamente ligado com a criação e troca de conhecimento, levando as organizações a estratégias tácitas (IDRESS, VASCONCELOS e ELLIS, 2018). A troca de informações é essencial para esse processo. Knoben, Oerlemans, Krijkamp et al. (2018) explorou e explicou a precisão da informação como um diferencial para as redes organizacionais e descobriu que as organizações podem se beneficiar e obter estratégias a partir dos diferenciais de precisão da informação. Eles explicam que a aprendizagem é inerente às redes pelo simples fato de que elas são estabelecidas a fim de operar de forma diferente do que as formas tradicionais de organização e considerar problemas que não podem ser abordados por uma única organização. Nessa perspectiva, as redes de empresas, na visão de Kogut (1988), surgem como uma resposta estratégica às mudanças ambientais e na perspectiva de seus membros alcançarem habilidades, conhecimentos e capacidade tecnológica por meio da aprendizagem.

Inerente à aprendizagem está o processo de inovação nas redes interorganizacionais. A inovação e as funções de troca de conhecimento e aprendizagem mencionadas anteriormente estão intimamente ligadas, uma vez que estas contribuem para a especialização das atividades e o conhecimento tácito que é particularmente valioso. De Rolt, Dias e Peña (2017) argumentam que as redes podem fornecer o conhecimento complementar crucial para a inovação e podem se tornar o mecanismo ideal para promover a inovação e o posicionamento competitivo. Westerlund e Rajala (2010) apontam que existe uma relação positiva entre a inovação de uma empresa e a colaboração em redes. Apesar de as redes serem constituídas, em muitos casos, por outros motivos, a inovação torna-se o propulsor da sustentabilidade dessas instituições (PEREIRA, VENTURINI, WEGNER et al., 2010). Junto com isso, Provan e Huang (2012) argumentam que a inovação é uma importante função das redes, pois é fundamental para a solução de problemas complexos. As inovações alcançadas nas redes interorganizacionais, seja por meio do aprendizado ou da especialização e padronização de certas atividades e / ou processos, levam a outro fator-chave, a legitimidade organizacional.

Segundo Suchman (1995, p. 574), a legitimidade pode ser definida como uma "percepção ou suposição generalizada de que as ações de uma entidade - organização ou rede organizacional - são desejáveis, adequadas ou apropriadas dentro de algum sistema socialmente construído de normas, valores, crenças e definições". Essa legitimidade é fundamental para o sucesso de uma organização e está relacionada à percepção gerada e socialmente construída com clientes, financiadores e organizações inseridas no ambiente institucional da organização/rede (PROVAN e LEMAIRE, 2012; ANDRÉ, 2013).

No contexto interorganizacional, Dimaggio e Powell (1983) mencionam que ao participarem de uma rede, as empresas passam a ser percebidas com "grandeza" em sua área de atuação, além de receber maior crédito e reconhecimento por parte do público. Isso, segundo esses autores, garante maior legitimidade nas ações empresariais e redimensiona a importância da empresa em seu contexto institucional. Para eles, os agentes interessados em estabelecer relações com uma determinada empresa geralmente esperam que essa empresa possa ter apoio político, recursos essenciais e estabilidade financeira. Diversos estudos têm desenvolvido o entendimento de que, trabalhando em redes colaborativas, é mais fácil convencer e obter apoio de interessados internos e externos para as atividades desenvolvidas devido à legitimidade alcançada pelo grupo (MCGUIRE, 2006; MILWARD e PROVAN, 2006; PROVAN e LEMAIRE, 2012; PAQUIN e HOWARD-GRENVILLE, 2013). 


\section{Proposição de um framework de interdependência entre redes e empresas}

Como pode ser visualizado nos dois tópicos anteriores, o foco da análise de dependência está centrado em duas abordagens: (1) como mecanismos sociais de interação influenciam a dependência da rede em relação às empresas integrantes, e (2) como os benefícios da atuação em rede tipicamente associados com o desempenho (poder de barganha; aprendizagem; inovação e especialização das atividades em rede; e legitimidade) determinam na relação de dependência empresa - rede. Esses fatores interagem no contexto cooperativo, e são delineados nesse trabalho como fatores de interdependência entre redes e empresas participantes. $\mathrm{O}$ framework proposto é ilustrado na Figura 1.

Figure 1

Framework dos fatores de interdependência entre redes e empresas

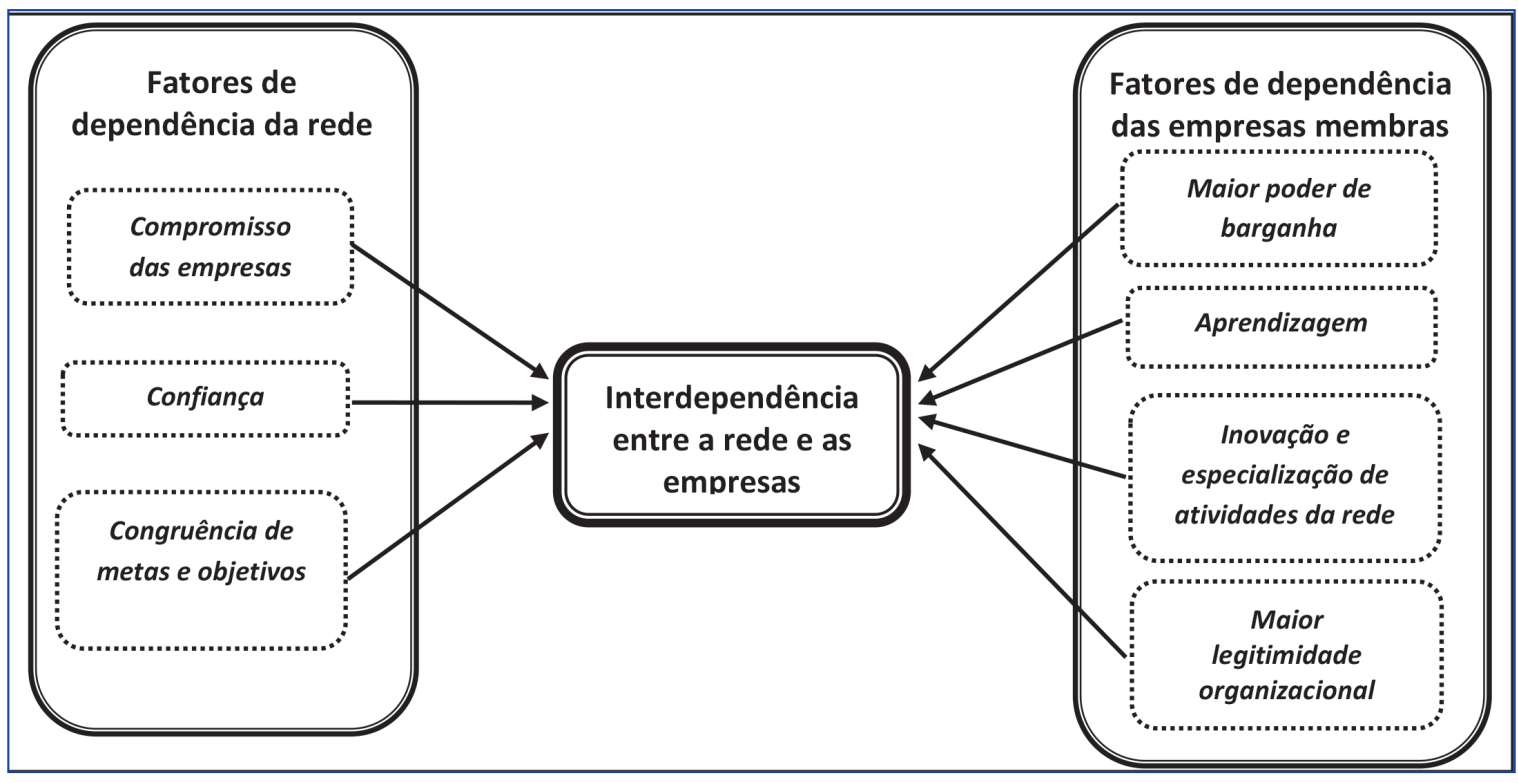

Fonte: Elaborado pelos autores.

O framework proposto visa possibilitar a compreensão dos fatores utilizados neste estudo para a interdependência entre as redes e empresas que a integram. Especificamente, a junção dos três fatores colocados no lado esquerdo da Figura 1 levaria a dependência da rede em relação às empresas. Já os quatro fatores posicionados ao lado direito da figura influenciam, em conjunto, a dependência das empresas com relação à rede. As setas no centro da figura indicam uma interação entre esses fatores ao longo da evolução das redes, e esses fatores determinam a relação de interdependência entre redes e seus membros.

A perspectiva da evolução das redes ao longo do tempo é adicionada a esta estrutura e será definida no método do estudo. Avaliar a interdependência das redes de acordo com seus estágios de evolução vai ao encontro do entendimento de Popp, Milward, Mackean et al. (2014), que mencionam que uma oportunidade significativa para o progresso de estudos e avaliação de redes reside na concepção e conexão de esforços de avaliação e métodos alinhados com os estágios de evolução da rede, usando todas as ferramentas de avaliação disponíveis e a adaptação e concepção de novas.

\section{Método do trabalho}

Este trabalho consiste em um estudo descritivo, pois há construtos bem definidos. Para elaboração deste trabalho, investigaram-se redes de empresas que estavam, no momento da coleta de dados, em três fases distintas de evolução, que são: a fase de Formação, a fase de Desenvolvimento e a fase chamada de Profissionalização das redes. Cada uma dessas fases foi identificada e diferenciada por meio das variáveis expostas na Quadro 1. Essas variáveis foram tomadas como critérios para atribuir as redes em cada estágio de desenvolvimento. Esses estágios de desenvolvimento da rede foram estabelecidos com base no artigo seminar de Provan e Kenis (2008), mas foram ajustados alguns ajustes para adotar cada etapa à realidade no Brasil. 


\section{Quadro 1}

\section{Aspectos chaves utilizados para análise das fases de evolução de redes}

\begin{tabular}{|c|c|c|c|c|}
\hline Variáveis & $\begin{array}{l}\text { Formação } \\
\text { da rede }\end{array}$ & $\begin{array}{l}\text { Desenvolvimento } \\
\text { da rede }\end{array}$ & $\begin{array}{l}\text { Profissionalização } \\
\text { da rede }\end{array}$ & $\begin{array}{l}\text { Autores de } \\
\text { referência }\end{array}$ \\
\hline $\begin{array}{c}\text { Modo de } \\
\text { governança }\end{array}$ & $\begin{array}{l}\text { Governança } \\
\text { compartilhada - } \\
\text { auto gerenciada }\end{array}$ & $\begin{array}{l}\text { Grupo de empresas } \\
\text { líderes com o apoio de } \\
\text { um ente administrativo }\end{array}$ & $\begin{array}{c}\text { Organização } \\
\text { Administrativa da } \\
\text { Rede (OAR) }\end{array}$ & $\begin{array}{c}\text { Provan e Kenis (2008); } \\
\text { Popp, Milward, Mackean et al. (2014) }\end{array}$ \\
\hline Liderança & $\begin{array}{c}\text { Centrada } \\
\text { nas empresas } \\
\text { integrantes em geral }\end{array}$ & $\begin{array}{l}\text { Dividida entre as } \\
\text { empresas líderes e o } \\
\text { ente administrativo }\end{array}$ & $\begin{array}{l}\text { Centrada } \\
\text { na OAR }\end{array}$ & $\begin{array}{l}\text { Provan e Kenis (2008); Dwyer, Schurr } \\
\text { e Oh (1987); Silvia e McGuire (2010) }\end{array}$ \\
\hline $\begin{array}{l}\text { Tomada de } \\
\text { decisões }\end{array}$ & $\begin{array}{l}\text { Descentralizada } \\
\text { entre os integrantes }\end{array}$ & $\begin{array}{l}\text { Relativamente } \\
\text { centralizada }\end{array}$ & $\begin{array}{l}\text { Centralizada } \\
\text { e Hierárquica }\end{array}$ & $\begin{array}{l}\text { Provan e Kenis (2008); Albers (2010); } \\
\text { Popp, Milward, Mackean et al. (2014) }\end{array}$ \\
\hline $\begin{array}{l}\text { Gestão das } \\
\text { atividades }\end{array}$ & $\begin{array}{l}\text { Sustentada em } \\
\text { mecanismos sociais }\end{array}$ & $\begin{array}{c}\text { Centrada nas empresas } \\
\text { líderes e no ente } \\
\text { administrativo }\end{array}$ & $\begin{array}{l}\text { Centrada } \\
\text { na OAR }\end{array}$ & $\begin{array}{l}\text { Provan e Kenis (2008); } \\
\text { Wegner e Padula (2010) }\end{array}$ \\
\hline $\begin{array}{c}\text { Estrutura } \\
\text { das relações }\end{array}$ & $\begin{array}{l}\text { Incipiente e dispersa } \\
\text { - há ligações de laços } \\
\text { fortes e fracos iniciais }\end{array}$ & $\begin{array}{l}\text { Definição de laços } \\
\text { fortes e fracos pelo } \\
\text { estabelecimento de } \\
\text { relações de confiança }\end{array}$ & $\begin{array}{l}\text { Manutenção de } \\
\text { laços fortes e fracos } \\
\text { e relações informais }\end{array}$ & $\begin{array}{l}\text { Provan e Kenis (2008); Granovetter } \\
\text { (1983); Provan e Lemaire (2012) }\end{array}$ \\
\hline
\end{tabular}

Fonte: Elaborado pelos autores.

Com base nesses critérios definidos na Quadro 1, foram realizadas entrevistas com os presidentes das redes selecionadas com base em sua disposição de participar do estudo. Assim, ao conduzir essas entrevistas, pode-se identificar, classificar e certificar em qual fase de evolução cada rede selecionada estava. Especificamente, classificou-se, por meio desses procedimentos de codificação, três redes no estágio de Formação, quatro redes no estágio de Desenvolvimento, e três redes na fase de profissionalização.

Uma vez feito isso, entrevistou-se o presidente de cada rede selecionada novamente para obter dados para verificar a dependência das redes em relação a suas empresas membras. Para isso, utilizou-se um protocolo de entrevista baseado nas variáveis apresentadas no lado esquerdo da Figura 1 e em sua literatura correspondente.

Uma terceira etapa do nosso estudo foi entrevistar empresários (membros) de cada rede selecionada. Esses empresários foram entrevistados para obter sua opinião sobre sua dependência com a rede, e para isso, um segundo protocolo de entrevista foi definido considerando as variáveis apresentadas no lado direito da Figura 1 e sua literatura correspondente. Nesta fase, decidiu-se entrevistar um membro recente (menos de 3 anos na rede) e um membro antigo (mais de 3 anos na rede) de cada rede, realizando um total de 20 entrevistados.

Dessa forma, foram entrevistados 10 presidentes de redes de empresas e 20 integrantes das redes pesquisadas. Para fins de análise das falas dos entrevistados, a identificação dos respondentes foi feita por meio de códigos com o intuito de manter seu anonimato. Dessa forma, os presidentes foram identificados como "Pres" e os membros integrantes como "M". Para diferenciar as fases de evolução em que cada uma das redes se encontrava, foi agregado o código " $F$ " quando a rede estava na fase de Formação, " $D$ " para a fase de desenvolvimento e "P" para a fase de profissionalização. Por fim, os presidentes tinham números identificadores de 1 a 4 e os integrantes de 1 a 8 (sendo 1 à 4 os integrantes recentes e 5 à 8 os integrantes antigos). Dessa forma, por exemplo, 'Pres $D$ 3', identifica impressões, opiniões ou respostas do presidente 3 de uma rede que está na fase de Desenvolvimento.

A análise dos dados foi baseada na técnica de análise de conteúdo. Para Bardin (2010) essa técnica pode ser considerada como um conjunto de técnicas de análise, que por meio de procedimentos sistemáticos e objetivos de descrição dos relatos dos entrevistados, busca a descrição do conteúdo das mensagens. De maneira geral, Flick (2009, p. 291) afirma que a análise de conteúdo "[...] é um dos procedimentos clássicos para analisar o material textual, não importando qual a origem desse material". 


\section{Apresentação e discussão dos resultados da pesquisa}

Nessa parte do trabalho, são apresentados os dados oriundos da pesquisa empírica realizada. A análise destes foi realizada de maneira comparativa entre as três fases de evolução definidas no método do trabalho.

\section{Análise da relação de dependência da rede}

Nessa subseção, são analisados os fatores estipulados como geradores da dependência da rede com as empresas integrantes. O primeiro dos fatores investigado junto aos presidentes das redes foi o comprometimento. Esse fator é citado por estudiosos sobre o tema como um dos importantes fatores necessários para a formação e manutenção de relações interorganizacionais.

Especificamente, nas redes com um modelo de governança compartilhada, como é o caso das redes em fase de Formação, a gestão da rede apoia-se no comprometimento e envolvimento dos membros. As redes nessa fase de evolução geralmente adotam esse modelo de governança auto gerenciada, pois como afirma Olson (1999), é um modelo que pode ter relativo sucesso em grupos menores, onde é possível maior controle sobre os membros, pressão de participação e a vantagem da inclusão de todos os participantes. Mas ele exige o comprometimento de todos como responsáveis pelo gerenciamento dos relacionamentos internos da rede e com os atores externos para sua efetividade. É isso que torna a rede dependente do comprometimento dos integrantes nessa fase.

Dois dos presidentes entrevistados dessa fase mencionam:

Tivemos que conversar com a equipe e destacar a questão da importância do comprometimento, que tem que haver esse comprometimento por parte de todos, senão a nossa rede não pode funcionar e crescer (Pres F1).

É fundamental esse comprometimento. É fundamental a pessoa se comprometer na participação, na transparência que ele vai ter. Ele vai ter que contribuir para todos e todos tem que contribuir para um. É um grupo que passa a ser formado. Não adianta dizer: a, nós vamos colocar um gestor, e ele vai administrar a rede e vai resolver todos os problemas para nós. Isso não funciona, as pessoas têm que participar, se comprometer (Pres F 3).

Para o funcionamento da rede nessa fase, suas atividades devem ser propostas e conduzidas com o auxílio dos integrantes, e nesse sentido, o comprometimento deles é essencial. É isso que os presidentes entrevistados enfatizam, como pode se verificar no relato destacado.

Paralelamente ao comprometimento dos integrantes com as atividades realizadas na rede, outro fator bastante referenciado na literatura sobre formação e desenvolvimento de redes é a confiança. Na fase de formação das redes, especificamente, a confiança também é um dos mecanismos sociais utilizados para a efetividade da governança compartilhada. Provan e Kenis (2007) afirmam que a confiança é essencial para o desempenho e efetividade de redes que usam esse modo de governança. Os presidentes disseram que a confiança é um fator chave na continuidade da rede.

O pessoal vai ter que ter é a confiança entre os colegas, por que, queira o não queira, todos estarão sabendo o que ele está produzindo, como ele está trabalhando, e quem são os seus clientes. E aí, os clientes dele e dos concorrentes dele, passam a ser os clientes da rede. Daí, se você está de férias, eu vou passar a atender teus clientes, o que antes não acontecia. Então a confiança é de suma importância para esse negócio que estamos realizando. A rede precisa disso, se não a gente não consegue vender nossa ideia (Pres F 1).

Sim, eu sei que posso comprar muitas coisas em nome de todos, e sei o que o outro vai pagar, isso é essencial para a rede, ainda mais como o nosso. Sem isso, não estaríamos fazendo nada. Então a confiança é muito importante. Eu acredito que a rede depende muito dela para existir (Pres F 2).

Nós temos confiança um no outro. Existe transparência, e para uma rede, para mim, se não tiver, não tem rede, não tem rede (Pres $F$ 3).

A confiança entre os integrantes nessa fase não é meramente a expectativa de que o outro assuma uma promessa estabelecida, mas que ele ajude a atingir os resultados esperados (CONKLIN e TAPP, 2003). Essa confiança entre os integrantes está relacionada a aspectos como acordos quanto às obrigações e às regras para a ação, a troca de informações e o próprio comprometimento em realizar as atividades conjuntas sem necessidade de mecanismos de controle. 
Outro fator a respeito do qual os presidentes das redes foram arguidos foi sobre a congruência quanto a metas e objetivos. Este fator é tido como elemento direcionador das propostas e perspectivas da rede. Alguns estudos exaltam esse fator ao apontarem a importância de critérios de seleção dos parceiros da rede devido à necessidade de alinhamento de recursos específicos e objetivos na rede (MOELLER, 2010).

Nas redes em fase de formação pode-se perceber uma clara relação de dependência da rede.

Na nossa rede é bem claro isso, por que se tu não cumpriu com a meta, tu não recebe os extras das seguradoras. [...] Então nossa meta é bem clara. Todo mundo tem que compreender esse nosso objetivo, $e$ trabalhar pra isso, pra que cada vez mais todos possam receber mais também. Esse é o fundamento, a base da nossa rede. Se o associado não entender isso, não vai adiantar pra ele e nem pra rede também (Pres F 1).

É essencial, sim, muito importante. Se o cara não entende por que nos reunimos, por que ele iria querer ficar com a gente? Até aquele momento, nossa rede não funcionou (Pres F 2).

Vale ressaltar que a forma de governança auto gerenciada tem maior probabilidade de funcionamento em redes que envolvam organizações mutuamente dependentes e que haja compatibilidade e complementariedade em seus objetivos. Por isso da necessidade desse fator para a efetividade das redes nesse estágio de sua evolução.

A análise inicial desses três fatores em redes que se encontravam na fase de formação mostra uma clara evidência da relação de dependência que a rede possui em relação a seus integrantes para o exercício de suas atividades e sua continuidade. Esse fato se deve basicamente ao modo de governança compartilhada adotada por essas redes e ao pequeno número de integrantes com que elas se formam. As redes estudadas nessa fase tinham, para se ter uma ideia, 4, 6 e 9 integrantes. Assim, caso algum dos integrantes não venha a se comprometer, por exemplo, a execução das atividades propostas e seu modo de gerenciamento ficam prejudicados.

No entanto, à medida que rede cresce, se desenvolve e evolui na organização de suas atividades, essa clara evidência não é mais tão facilmente percebida. Numa análise comparativa com as outras fases da evolução definidas para este artigo, percebe-se que essa relação de dependência diminui, até praticamente inexistir na fase de profissionalização da rede.

Quanto ao comprometimento, dois dos presidentes de redes da fase de Desenvolvimento mencionam o seguinte:

Teríamos que ter mais pessoas envolvidas e comprometidas. Tem muitas pessoas na nossa rede que só esperam as coisas acontecerem. [...] Tem pessoas que nem no horário marcado chegam nas reuniões. Isso é algo que falta de alguns. Mas a gente vai conseguindo fazer as coisas mesmo assim. Existem outros membros que nos ajudam e movem muito a rede (Pres D 3).

o comprometimento dos membros nem sempre acontece. O grupo ficou grande, e nem todos se envolvem como esperávamos. Este é um dos problemas da nossa rede. Estamos no mercado há 9 anos, temos problemas de rede e um deles é essa falta de compromisso. Mas podemos continuar de qualquer maneira (Pres D 1).

Esses relatos já mostram que, diferentemente da fase de formação das redes, o não comprometimento de um integrante não compromete significativamente as atividades da rede. $\mathrm{O}$ entrevistado menciona que a rede consegue prosseguir com suas atividades na falta de comprometimento de um ou outro integrante.

Na fase de Profissionalização, os presidentes entrevistados são ainda mais enfáticos quanto a não dependência em relação a seus associados.

A associação da rede, assim, da maneira que nós organizamos, com a estrutura da diretoria e seu conselho, isso jamais vai se quebrar, porque não temos dependência mais dos associados, mesmo que não se comprometam (Pres $P$ 2).

A rede não se preocupa com isso, se alguém não se compromete, porque tem uma estrutura que, se deixar um ou dois, os demais podem se manter bem. E a rede sempre trabalha com valor x em dinheiro, até mesmo para responder a essas perguntas lá (Pres $P$ 3).

Para estes presidentes, a estrutura da rede está organizada de tal forma que mesmo que caso os integrantes não se comprometam, ela continuaria suas atividades. 
Isso está muito vinculado aos benefícios gerados por essas redes, que serão explicitados na subseção seguinte. Em outras palavras, as atividades organizadas pelas redes mais evoluídas geram benefícios que são tão importantes aos seus integrantes, que invariavelmente eles têm de se comprometer. Por isso que a relação de dependência da rede quanto a esse fator diminui conforme ela se estrutura e evolui.

A mesma análise pode ser feita quanto à questão da confiança. Alguns presidentes de redes na fase de Desenvolvimento mencionam:

Se não há confiança entre um ou outro, aqui, a nossa rede não acaba. Tem aquele integrante que te falei no início, que a gente acaba fazendo vista grossa pra ele, para as coisas que vem dele. E todo mundo já sabe do jeito dele (Pres D 4).

Posso dizer, então, que a grande maioria confia um no outro. Claro, faremos tudo que pudermos para confiar em todos e não deixar a rede, mas isso não acontece [...] Não, a rede não acaba se um a deixar, mas queremos mantê-lo junto (Pres D 1).

Alguns presidentes de redes da fase de Profissionalização relatam:

Hoje, a rede está estabilizada. A dependência hoje, eu tenho conviçcão, até falando da minha empresa de supermercado, que a dependência é muito maior do supermercado em relação à rede, do que a rede em relação ao meu supermercado (Pres $P$ 1).

Há o dono, que tem seu próprio farmacêutico, e não quer saber sobre o outro. Ele aproveita o que é bom para ele, o que é ruim, ele nem dá horas. Essa é a nossa grande dificuldade, mas fazer o que. Então, não podemos confiar nesse cara, não podemos (Pres $P$ 2).

Por esses relatos pode-se notar que a confiança entre os integrantes passa a não ser mais requisito necessário para manter a rede ativa no mercado. $O$ fato que ocorre aqui é que com a evolução da rede, e a geração de recursos e benefícios que são essenciais aos integrantes, a confiança passa a não ser mais necessária entre os integrantes, e sim nas atividades e oportunidades geradas pela rede. Como os integrantes, de maneira geral, não fazem mais parte da estrutura de governança da rede, e se afastam da gestão da rede, eles têm de depositar certa confiança no fato de que a rede possa ser o mecanismo de geração de benefícios e recursos que ele necessita.

Por fim, ao serem avaliadas as repostas sobre a congruência quanto a metas e objetivos, pode-se verificar que a questão de dependência da rede com seus integrantes também diminui, como mostram os relatos a seguir:

Se tiver alguém puxando para outro lado, a rede não tem por que existir para aquela pessoa. Se ela optar por outro lado, a gente até tentar puxar ela de volta, para coletividade. Mas se ela não que vir, aí não tem o que fazer. Ela segue o caminho dela, a gente segue o nosso e buscamos no mercado uma empresa ou mais que tenham a mesma visão que a gente (Pres D 2).

Então essa questão de todos pensarem de forma semelhante, tendo o que a rede procura em mente, é algo que ajuda muito a rede sem dúvida. Eu e outros camaradas, nós batemos muito em cima disso, e nós conseguimos muito, muitos cursos para nós, mesmo que alguns não participem e não tenham isso em mente (Pres D 3).

Nós respeitamos as diferenças, porque temos lojas centenárias. Mas, para nós, é importante acrescentar, porque quanto mais membros nos afiliamos em um perfil de nossa rede, maior o poder de compra, maior o poder de barganha com os fornecedores, mais opções temos quando fazemos uma promoção. O membro tem que entender isso e se encaixar no perfil da rede, caso contrário nós não aceitamos ou nos desconectamos (Pres $P$ 3).

A partir desses relatos, pode-se compreender que a rede, na medida em que se desenvolve e evolui, busca alinhar o perfil e metas do associado às metas da rede. Shipilov Rowley e Aharonson (2006) destacam em seus estudos a necessidade de os potenciais integrantes e parceiros de uma rede alinharem suas atividades aos objetivos e à estratégia da rede e tenham um perfil adequado para adaptar-se à cultura cooperativa. Mas, caso isso não aconteça, as atividades da rede, principalmente na fase de profissionalização, são continuadas mesmo que um determinado integrante não se adeque àquele perfil e objetivo. 
Nessas fases evolutivas de Desenvolvimento e, principalmente, de Profissionalização das redes, o que se pode verificar, de maneira geral, é que esses fatores analisados não se tornam menos importantes que na fase de Formação das redes. Eles continuam sendo importantes, mas a rede não é mais tão dependente deles para exercer suas atividades. O que ocorre é que com o crescimento da rede em número de integrantes e a melhor organização de suas atividades, a saída de um ou outro integrante não prejudica significativamente a execução dessas atividades, pois os outros integrantes dão sustentação à rede.

\section{Análise da dependência das empresas}

Em relação aos aspectos influenciadores da dependência das empresas da rede, o primeiro fator a ser questionado aos entrevistados foi o poder de barganha. Este fator é relacionado em várias pesquisas como principal vantagem competitiva proporcionada as empresas integrantes de redes. O poder de barganha, conforme explicitado no referencial teórico, proporciona aos integrantes maior capacidade de conseguirem preços menores para as matérias primas ou mercadorias que utilizam, uma vez que, ao comprarem em conjunto grandes quantidades, pressionam o fornecedor a oferecer um preço menor. Por esse motivo é que esse fator é estudado nesse trabalho como um influenciador da dependência das empresas integrantes de redes.

Nas redes que estão na fase de Formação, no entanto, esse fator não foi considerado como algo que gerasse a dependência das empresas com a rede. As falas de alguns entrevistados mostram isso:

Como nós somos empresas pequenas, nenhuma da conta de comprar uma grande quantidade sozinha. Então quando nós vemos que tem um material que a gente usa bastante, a gente compra junto. Fora isso, quando a gente compra pouco material, daí a gente compra de forma independente, daí é algo fora da rede. Então, a gente consegue maior poder de barganha sim, quando a gente compra junto, mas a gente não é dependente da rede por isso (M F 3).

Então é uma coisa boa para nós. Mas, como você me perguntou antes, o que aconteceria se a rede acabasse ... eu compraria eu mesmo. Eu tenho um crédito no mercado e minha empresa nunca terminaria se a rede deixasse de existir ( $M F 1$ ).

Então, com o sindicato, conseguimos taxas melhores e mais competitivas e nos tornamos mais competitivos no mercado. Isso porque, antes, só tínhamos o argumento de oferecer um seguro mais completo, e hoje também temos preços melhores. É algo que quando termos mais membros, nos tornará mais fortes e competitivos, e com um link com a rede, será difícil dissociar (M F 4).

Portanto, há poucas coisas, porque já conhecemos nossos clientes e clientes de outras pessoas em nossa cidade, o que os outros compram, em que meu produto difere do outro. Minha empresa não terminaria se a rede não existisse, porque já nos estruturamos individualmente, e isso seria tranquilo (M F 6).

Pela fala destes entrevistados pode-se verificar que esse fator é realmente uma vantagem deles trabalharem em rede, mas não ao ponto de gerar uma dependência em relação à rede. A maioria dos entrevistados enfatizou que, apesar dessa vantagem gerar um diferencial para eles, a empresa e os negócios deles não terminariam caso eles não pudessem mais auferir esse benefício por causa de um eventual término da rede.

Nas redes em fase de Desenvolvimento e, mais especificamente na fase de Profissionalização, a avaliação deste fator entre os integrantes já é diferente. Na medida em que as redes se desenvolvem, torna-se mais efetiva a possibilidade dos associados dessas redes poderem comprar conjuntamente equipamentos, ferramentas, cursos e matéria prima, gera a eles uma oportunidade de negociarem com os fornecedores questões como preço, prazo e formas de pagamento. $O$ relato de alguns dos integrantes resume essa situação:

Então a diferença que minha empresa fez para estar na rede é pelo menos cinco por cento de diferença em relação a se eu não estivesse na rede. Se eu não estivesse na rede, certamente não teria alcançado esses valores. Então, isso é uma coisa essencial para mim e que a rede me fornece (M D 7).

Nós fizemos pacotes de compra de equipamentos de injeção eletrônica, scanner e outros. Houve uma vez que compramos 7 equipamentos, e além de um desconto, tínhamos um prazo. Então, a rede dá essa vantagem ao associado, se comparado ao comprador independente, certo (M D 6).

A questão econômica nem se fala, por que tu imagina mais de 700 lojas todas comprando junto, negociando com um fornecedor. Você tem um poder de barganha muito maior do que se você está independente 
e trabalhando sozinho. Daí, assim ó, sem sombra de dúvidas que o associativismo, como é o caso da nossa rede, é o caminho para o pequeno, para as pequenas empresas, que é o meu caso (M P 1).

Digamos que compramos 100.000 unidades, o fornecedor me dá 10\%, compramos 500.000 unidades, eu recebo $15 \%$ de desconto, 1 milhão de unidades me dá 20\%. A pequena farmácia não pode comprar 1 milhão. Mas somos 720 lojas e 1 milhão de unidades para nós é isca. Você me entende? Então essa é a grande dependência de farmácias independentes hoje (M P 5).

Essas condições geram uma situação de compra que uma empresa individual não conseguiria, o que é essencial para a manutenção de sua empresa. Em virtude disso, essas empresas acabam se tornando dependentes da rede em que estão inseridas.

Outro fator questionado aos entrevistados foi a aprendizagem e troca de informações entre os integrantes da rede. A aprendizagem com os outros integrantes da rede surge, muitas vezes, do trabalho com outra organização ou no desenvolvimento de uma compreensão comum de um problema para chegar a um consenso sobre como lidar com ele (GRAY, 2000). Essa parceria entre os integrantes pode aumentar efetivamente o aprendizado e a capacidade delas na prestação dos seus serviços e atividades, bem como na oferta de seus produtos para competir com o mercado.

Para os integrantes das redes estudadas na fase de Formação, a troca de informações e a aprendizagem foram citadas de diferentes formas, e como algo benéfico para eles. Mas, notou-se que nada foi mencionado no sentido de se poder estabelecer de um vínculo de dependência dessas empresas com a rede. Alguns dos integrantes mencionam:

A gente troca ideias, conversamos bastante sobre o serviço, mas nada que nos torne dependente. $A$ gente não é dependente da rede, nada, nada, nada dependente ( $M$ F 2).

Então, é bom que um parceiro tenha o contato que temos entre nós, mas nada demais ( $M F 6$ ).

Então, sobre esse aprendizado que você disse, eu não sou dependente de rede. Mas indiretamente eu continuaria a trocar informações com eles, continuaria a esclarecer minhas dúvidas com eles (M F 3).

Os estudos sobre redes têm demonstrado que elas podem se tornar um ambiente no qual os integrantes trocam experiências, práticas de trabalho e gestão, conhecimento e informações em geral que podem, não somente agregar ao negócio dessas empresas, mas também que gere diferenciais competitivos a esses integrantes na forma de inovação e aprendizagem. No entanto, Schulz e Geithner (2010) explicam que a aprendizagem e o desenvolvimento em rede dependem de alguns fatoreschave, incluindo a composição e o número de participantes e a suficiência de recursos a nível operacional para ser capaz de desenvolver novas formas de trabalhar. Em geral, certos elementos são necessários para que uma empresa integrante de rede obtenha reais vantagens competitivas por meio da aprendizagem a partir da rede, e que isso a torne realmente dependente da rede.

Especialmente em relação aos integrantes das redes na fase de Desenvolvimento ou Profissionalização, a aprendizagem proporcionada pela rede por meio de cursos e palestras é essencial e gera novos conhecimentos aos integrantes. São questões essenciais e que impactam diretamente nos negócios desses integrantes. Alguns deles afirmam:

Essa é a maior conquista que temos, e se tenho prazer em estar na rede, é nesse sentido, de ter uma dúvida ou não saber alguma coisa e a equipe saber dar informações sobre como fazer. O conteúdo, a troca de informações, isso para mim é essencial (M D 2).

Uma das principais razões para formar a rede é a busca por informações e a atualização da profissão. Olha, eu diria que isso é mais importante do que comprar juntos, porque precisamos melhorar nossa atividade, para nos mantermos atualizados no nosso dia a dia de trabalho (M D 6).

Nós vamos fazer cursos de tributação, legislação e fiscalização. Três coisas que impactam dentro do nosso negócio. A fiscalização, a vigilância sanitária está permanentemente em cima, nós precisamos. Pra ti ter uma ideia, uma nota fiscal, hoje, ela traz 14 tributações diferentes (M P 5).

Esses relatos mostram que a questão da aprendizagem na rede é um fator que gera competitividade para as empresas integrantes, principalmente em relação às informações e situações de mercado, como ressalta o entrevistado M P 5. A aprendizagem proporcionada pela rede gera acesso mais rápido e fácil a informações, bem como torna o integrante e seus colaboradores sabedores de técnicas e normativas de gestão que são essenciais para a melhor condução dos seus negócios. 
As questões de tributação, legislação e fiscalização que as empresas têm de se preocupar, expostas pelo entrevistado M P 5, seriam mais difíceis de serem conhecidas pelos membros caso não estivessem inseridos na rede.

Vinculado a esse fator discutido está à especialização das atividades e inovações proporcionadas pelas redes. Esta é uma das principais medidas de geração de diferenciais competitivos para as empresas que atuam em redes. Conforme conceituado anteriormente, a inovação pode ser entendida de diversas formas, desde a introdução de um novo bem no mercado ou de um novo método de produção, até a conquista de uma nova fonte de matérias primas ou bens ou abertura de um novo mercado ou organização (SCHUMPETER, 1911). Sua característica principal está vinculada a aplicação comercial ou organizacional de alguma coisa nova, que é desconhecida para as empresas até então.

Esse fator, no entanto, não foi citado pelos integrantes das redes na fase de Formação. Eles apenas mencionaram que a rede ainda não inova e não gera ações ou atividades especializadas aos negócios de suas empresas. Dois deles afirmam: "Bom, nessa questão cada um tem o seu modo de trabalhar e cada um lida com a suas dificuldades por conta. Não tem muita relação da rede" (M F 1). "Mesmo que tenhamos nosso próprio foco, obtemos informações de alguém do grupo que fez uma melhoria, ou o que ele fez de uma maneira diferente. Nada muito essencial para nós (M F 5)".

Na fase de Desenvolvimento e, principalmente, da fase de Profissionalização, os entrevistados foram mais enfáticos e apontaram situações que as inovações da rede tornam as empresas dependentes. Seguem alguns relatos:

Temos na rede, são profissionais que têm capacidade técnica para ministrar cursos aos nossos funcionários. Por exemplo, temos um membro da rede, que ele é um assistente autorizado da Bosch e ele é capaz de dar curso de ultímetro, a parte elétrica, para nossos funcionários. [...] Mesmo assim, no 5S, aplicamos muito nas nossas empresas, e fica a sensação de limpeza, senso de organização, que torna o dia a dia de cada um muito mais organizado (M D 3).

Nisso o que a rede nos ajudou é primeiramente em questão de sistema. Esse sistema permite fazer um gerenciamento de estoques, gerenciamento de perdas, controle de validade, controle de lotes de medicamentos, fazer a rastreabilidade. Então, isso é feito hoje na minha loja, eu consigo acompanhar tudo isso, pra tu ter uma ideia. E isso eu só consegui ter depois que eu entrei na rede e pude ter acesso a esse sistema, que permite fazer isso aí. Então, não é só pelas compras que sou dependente (M P 1).

No sistema de rede tem tudo também. Tem um prazo de pagamento, sua validade, tem o tipo de entrega, se será entregue na loja ou no depósito central, se a nota é da rede ou se é faturada diretamente para nós. Tem esses detalhes bem aqui. É algo que a rede me forneceu e não vejo como posso trabalhar sem ela. É demais (M P 2).

Nós cuidamos do seu pedido em sua casa, você não precisa sair de casa. Nós Ihe enviamos uma pequena máquina para pagar com o cartão na casa. Então, essas instalações nós colocamos e estamos criando coisas novas e diferentes que os outros não têm (M P 5).

O fato a ressaltar quanto a esse resultado é que a geração de recursos e atividades novas, que as empresas integrantes dificilmente conseguiriam fora da rede é, geralmente, obtida na medida em que a rede especializa suas atividades e inova. A literatura de redes e de inovação mostra que as empresas que pertencem às redes são mais inovadoras do que as empresas que atuam sozinhas (AHUJA, 2000). Só que para isso, é necessário certo tempo para estruturação da rede, organização das atividades e obtenção dos objetivos básicos a que a rede se propõe.

Por fim, o último fator estudado nessa subseção se refere à questão de legitimidade organizacional adquirida pela atuação na rede. Aqui, refere-se à legitimidade externa da empresa, aquela conseguida perante seus principais stakeholders. A questão essencial investigada está relacionada ao quanto as empresas passam a serem mais bem vistas no mercado e melhoram sua imagem e prestígio perante clientes, fornecedores, investidores e demais envolvidos.

Os empresários entrevistados das redes na fase de Formação mencionam certos elementos que podem ser o passo inicial para construção dessa legitimidade. Dois deles afirmam que: "[...] a gente chegou a padronizar algumas coisas pra tentar buscar uma identidade da rede. Fizemos uniforme para todos, fizemos uma placa para colocar nas empresas e identificar a rede, mas isso acabou meio que não dando certo, e cada um já faz a suas coisas por conta mesmo (M F 3)". "Então, estamos criando uma imagem nesse sentido, mas não que dependamos dela, até pelo tempo que temos de mercado (M $F$ 4)". São práticas que, no longo prazo, conforme a rede for se estruturando, podem se tornar reconhecidas pelos interessados na rede 
e conduzi-la a gerar uma legitimidade organizacional. No entanto, nenhum entrevistado mencionou algo que remetesse a dependência da empresa com a rede.

A legitimidade é, em sua essência, um recurso simbólico que, geralmente, não é possuído pela organização antes de entrar na rede. Ela é criada a partir das ações da rede, pelas relações estabelecidas com os stakeholders e pelo sistema de normas e valores construído e ancorado na rede. Nas redes em fase de Profissionalização, os relatos indicam a consolidação de uma legitimidade na rede, e que está impacta diretamente nos negócios das empresas integrantes. O relato de alguns integrantes dessas redes mostra isso:

Eu acho que isso é bom para os dois lados. Para a rede, as pessoas passam e vêem: 'bah, a empresa também faz parte da rede'. E para mim, eu acabo recebendo mais imagem do que antes, as pessoas vêm ver a minha empresa pelo trabalho da rede. Então, agora, é uma troca dupla, é bom para mim e é bom para a rede também (M D 8).

Eles procuram a rede, porque sabem o papel da rede e sabem a seriedade que a rede tem e das condições que a rede tem. A rede sempre preza por isso, que é pagamento $100 \%$ em dia, nossa credibilidade, não deixa nada ficar em atraso. Isso são coisas que a gente sempre pregou e que o fornecedor sabe disso e por isso nos traz bons negócios (M P 2).

Sim, por exemplo, temos um grande respeito pelos fornecedores e eles por nós. Lembro que quando chegamos em feiras e todos com camisetas da rede, eles dizem: "Ah, os caras da rede chegaram ..." [...] Então, quando você faz parte da rede, como nós hoje, você tem o reconhecimento dos fornecedores e também dos vendedores que fazem parte deles (M P 6).

Hoje, sabemos que a rede é reconhecida nacionalmente, porque os gestores vêm de nível nacional daqui querendo entrar no Rio Grande do Sul para vender algum produto na região. Eles procuram a rede porque conhecem o papel da rede e sabem o quanto a rede é séria e as condições da rede (M P 5).

O fato de a legitimidade organizacional ser construída ao longo da evolução da rede, por si só, já explica por que redes em fase de formação não possuem esse recurso simbólico. Ademais, Provan e Sydow (2009) afirmam que elementos como capacidade de aquisição de recursos e desempenho financeiro contribuem para a legitimidade nas relações interorganizacionais. Para Human e Provan (2000), a aceitação da rede por seus membros e atores externos como geradora de status e credibilidade em suas atividades, a partir de comprometimento e suporte a recursos chave, é que gera a legitimidade e vai determinar se a rede pode sobreviver ao longo do tempo como uma forma interorganizacional.

\section{CONSIDERAÇÕES FINAIS}

O objetivo geral deste artigo foi o de verificar como se desenvolve a relação de interdependência rede-empresa e empresarede ao longo da evolução das redes interorganizacionais. A partir dos resultados dessa pesquisa, pode-se obter alguns insights sobre este objetivo.

Primeiramente, pode-se verificar uma clara inversão nessa relação de interdependência entre as partes. As redes, em sua fase inicial de Formação são dependentes de seus integrantes quanto aos mecanismos sociais de controle, como o comprometimento e a confiança, bem como quanto à congruência de metas e objetivos. Como Xia, Wang, Lin et al. (2016) argumentam que os fatores sociais dos membros da rede estimulam e motivam as empresas a responderem à lógica da dependência e às necessidades que surgem durante a formação da cooperação. Além do mais, nessa fase, as redes possuem um pequeno número de integrantes e, geralmente, adotarem o modo de governança compartilhada para o gerenciamento de suas atividades. Especialmente nesse estilo de governança, os elementos investigados são de suma importância para a efetividade das atividades propostas (PROVAN e KENIS, 2007).

Nos estudos de Tubin e Levin-Rozalis (2008), eles descrevem que a cooperação é construída através da interação social ao longo do tempo, com uma cultura corporativa compatível e normas compartilhadas. Isso está em consenso com Dickel, Hörisch e Ritter (2018), que descrevem que os valores sociais e a interação dão às empresas uma compreensão parecida dos 
recursos necessários para o trabalho em rede. Além disso, a confiança entre os parceiros de cooperação e troca de informações aumentam, como Oliveira, Borges, Carvalho et al. (2016) enfatizam.

No entanto, à medida que as redes evoluem, tornam-se maiores em número de integrantes e utilizam formas de governança mais formais (como as que utilizam OARs) são prováveis de se tornarem mais eficazes do que as redes com governança compartilhada (PROVAN e KENIS, 2007). Nesses modos de governança, a dependência das redes em relação aos seus integrantes diminui, como se pode verificar na pesquisa empírica realizada. Nesses estágios mais evoluídos, as redes fornecem benefícios adequados e preenchem as necessidades de recursos de membros (como os descritos por CENTENARO e LAIMER, 2017 e DEBOÇÁ e MARTINS, 2015), que eles não conseguiriam sozinhos no mercado. O desafio para as redes nessas fases e com esses modos de governança está nas competências exigidas para responder às necessidades de recursos das empresas.

Aqui, é importante notar que a evolução da rede e o uso de estruturas de governança mais formais andam de "mãos dadas". Em outras palavras, para manter as atividades e atingir os objetivos planejados, são necessários maiores esforços de tempo, organização, coordenação e controle, aumentando o nível de competências gerenciais necessárias. Como resultado, as redes tendem a adotar modos de governança mais formais, como organização líder e organização administrativa de rede (PROVAN e KENIS, 2008). Com relação ao desenvolvimento de estruturas de governança, Isett, Mergel, LeRoux et al. (2011) mencionam uma tendência descrita na literatura de que as redes começam com uma estrutura comum e informal e tendem a se tornar mais formais ao longo do tempo.

Para ilustrar a diferença e a mudança da relação de interdependência investigada nesse trabalho, elaborou-se a Figura 2. Nela é representado o "comportamento" da relação de interdependência das redes e das empresas integrantes ao longo das fases de evolução das redes estudadas.

Figura 2

Relação de interdependência rede - empresa

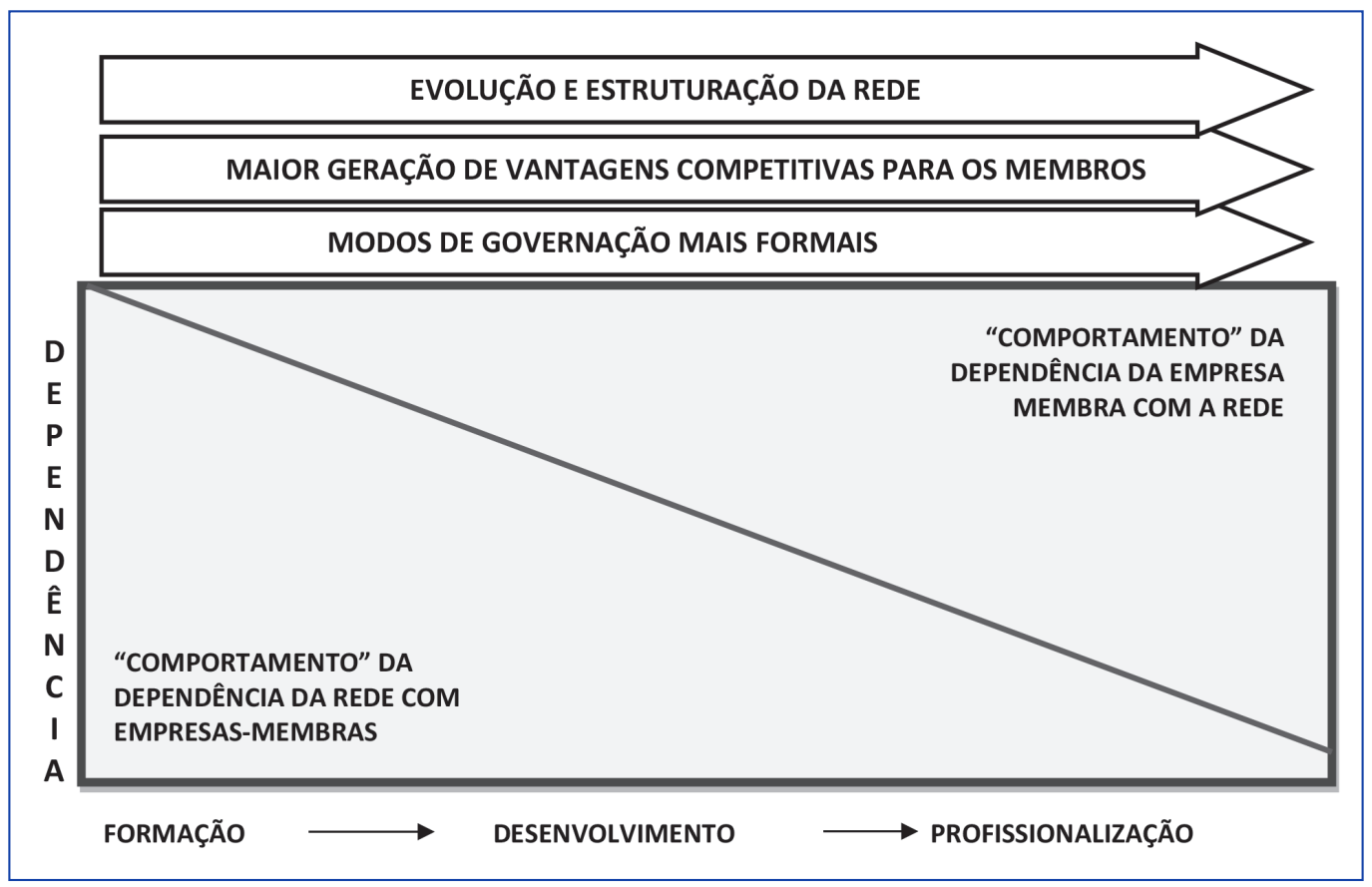

Fonte: Elaborado pelos autores.

O que se pretende representar com a Figura 2 é exatamente o que pode ser visto no decorrer da apresentação dos resultados, ou seja, a inversão na relação de interdependência entre as redes e as empresas integrantes. Em outras palavras, a dependência da rede é alta na fase de Formação e vai diminuindo ao longo do tempo com a sua evolução. Já com as empresas, ocorre o oposto. Sua dependência vai aumentando com a evolução da rede e conforme ela vai se tornando mais bem estruturada. 
Mais especificamente, a resposta que a rede proporciona com a sua evolução em relação aos recursos de que os integrantes das redes necessitam é que acaba gerando uma inversão na relação de dependência das empresas. Estas, ao entrarem na rede, buscam apenas oportunidades de melhoria de seus negócios a partir dos benefícios gerados pela rede. Mas, a partir do momento que a rede começa a melhorar sua organização e estrutura gerencial e passa a gerar recursos únicos às empresas integrantes, estas vão se tornando cada vez mais dependentes da rede em que estão inseridas. Em geral, os recursos de que elas necessitam não são encontrados fora de uma rede.

Na teoria, dado o fato de as organizações transacionarem umas com as outras para obter os recursos necessários, o controle sobre estes passa a exercer papel chave na relação, pois ele fornece poder sobre a outra organização, que se torna dependente (PFEFFER e SALANCIK, 1978). Em outras palavras, uma organização pode ser influenciada por outra que detenha o controle substancial ou exclusivo sobre os recursos que são críticos para a sobrevivência dessa organização, que nesse caso é a rede. $\mathrm{Na}$ prática isso ficou claro por meio da pesquisa empírica realizada. À medida que as redes proporcionavam diferenciais competitivos aos seus integrantes, por meio de fatores como o poder de barganha, a aprendizagem, as inovações e a legitimidade organizacional, eles se tornam dependentes da rede em que estavam inseridos.

Outro ponto a ressaltar é que por mais que as empresas busquem estratégias para evitar que sejam controladas e que percam sua autonomia, a dependência aos recursos gerados por uma rede não deve ser entendida como algo prejudicial à organização integrante. Se a rede é o caminho pelo qual a empresa obtém os recursos críticos para sua sobrevivência e gerar lucro ao seu negócio, o fato de essa empresa ser dependente da rede passa a ser motivo para empresas comprometer-se e colaborar ainda mais para o sucesso das ações empreendidas pela rede. Para Gardet e Mothe (2012) a dependência surge da necessidade da empresa manter uma relação colaborativa a fim de atingir os seus objetivos. Assim, a partir do momento em que a rede é efetiva em proporcionar o alcance desses objetivos organizacionais e disponibilizar uma gama de recursos para diminuir a incerteza da empresa em relação ao ambiente, ela torna-se um veículo efetivo de competitividade de suas empresas integrantes, e as empresas devem colaborar para que ela continue sobrevivendo.

Estes resultados delineados nesse estudo contribuem para uma abordagem mais abrangente dos mecanismos e fatores que influenciam a compreensão do processo de evolução das redes, que se solidificam e atuam como uma empresa individual separada das organizações integrantes na medida em que evoluem. Essa tendência verificada nesse trabalho leva ao entendimento de que as redes podem se tornar organizações que, assim como as demais, necessitam de investimentos nas principais áreas da administração, como finanças, marketing, gestão de pessoas e materiais.

Além disso, expande-se um espectro de novas possibilidades de pesquisa, como: como se dá a relação de poder que a rede exerce sobre seus integrantes? O ramo de atividade da rede está relacionado com a maior ou menor dependência das empresas integrantes? Como otimizar o desenvolvimento de diferenciais competitivos para manter as empresas integrantes vinculadas? 


\section{REFERÊNCIAS}

ANDRÉ, M. R. D. L. Factores de sucesso nas redes interorganizacionais de carácter temporário. 2013. 289f. Tese (Doutorado em Ciências Sociais) - Universidade Técnica de Lisboa, Lisboa, Portugal, 2013.

AHUJA, G. Collaboration networks, structural holes, and innovation: a longitudinal study. Administrative Science Quarterly, v. 45, p. 355-425, 2000.

ALBERS, $\mathrm{S}$. The design of alliance governance systems. Köln: Kölner Wissenschaftsverlag, 2005.

ANDERSEN, P. H.; MEDLIN, C. J. Transient commitments and dynamic business networking. Industrial Marketing Management, v. 58, n. 1, p. 11-19, 2016.

ANDERSON J. C.; NARUS, J. A. A model of distributor firm and manufacturer firm working partnerships. Journal of Marketing, v. 54, n. 1, p. 42-58, 1990.

ANDRÉSEN, E.; LUNDBERG, H.; ROXENHALL, T. Designing for commitment in regional strategic networks. Management Research Review, v. 35, n. 6, p. 531-552, 2012.

BARDIN, L. Análise de conteúdo. Lisboa: Edições 70, 2010.

CARVALHO, J. F. et al. A cooperação entre redes de pequenas empresas: antecedentes, etapas e resultados da estratégia de intercooperação. REGEPE - Revista de Empreendedorismo e Gestão de Pequenas Empresas, v. 7, n. 1, p. 35-70, 2018.

CASTRO, M.; BULGACOV, S.; HOFFMANN, V. E. Relacionamentos interorganizacionais e resultados: estudo em uma rede de cooperação horizontal da região central do Paraná. Revista de Administração Contemporânea (RAC), v. 15, n. 1, p. 25-46, 2011.

CENTENARO, A.; LAIMER, C. G. Relações de cooperação e a competitividade no setor supermercadista. Revista Brasileira de Gestão de Negócios, v. 19, n. 63, p. 65-81, 2017.

CONKLIN, D.; TAPP, L. A rede criativa. In: CHOWDHURY, S. Administração do século XXI: o estilo de gerenciar hoje e no futuro. São Paulo: Pearson Education, 2003. p. 220-234.

DE ROLT, C. R.; DIAS, J. D. S.; PEÑA, F. T. G. Network analysis as a management tool for inter-organizational projects. Gestão \& Produção, v. 24, p. 266-278, 2017.

DEBOÇÁ, L. P.; MARTINS, R. S. Vantagens Competitivas Originadas dos Relacionamentos Horizontais em Aglomerações Produtivas: percepções de atores locais. Revista Brasileira de Gestão de Negócios, v. 17, n. 56, p. 1025-1043, 2015.

DICKEL, P.; HÖRISCH, J.; RITTER, T. Networking for the environment: The impact of environmental orientation on start-ups' networking frequency and network size. Journal of Cleaner Production, v. 179, p. 308-316, 2018.

DIMAGGIO, P. J.; POWELL, W. W. Institutional isomorphism and collective rationality in organizational fields. American Sociology Review, v. 48, p. 147-160, 1983.

DIRKS, K. T. The Effects of Interpersonal Trust on Work Group Performance. Journal of Applied Psychology, v. 84, p. 445-455, 1999.

FLICK, U. Introdução à pesquisa qualitativa. 3a ed. São Paulo: Artmed, 2009.
GARDET, E.; MOTHE, C. SME dependence and coordination in innovation networks. Journal of Small Business and Enterprise Development, v. 19, n. 2, p. 263-280, 2012.

GRAY, B. Assessing interorganizational collaboration: multiple conceptions and multiple methods. In: FAULKNER, D.; ROND, M. (Eds.) Cooperative strategy: economics, business and organizational issues. London: Oxford University Press, 2000. p. 243-260.

GULATI, R.; SYTCH, M. Dependence Asymmetry and Joint Dependence in Interorganizational Relationships: Effects of Embeddedness on a Manufacturer's Performance in Procurement Relationships. Administrative Science Quarterly, v. 52, n. 1, p. 32-69, 2007.

GUNDLACH, G. T.; ACHROL, R. S.; MENTZER, J. T. The structure of commitment in exchange. Journal of Marketing, v. 59, n. 1, p. 78-92, 1995.

HERNANDEZ, E.; SHAVER, J. M. Network Synergy. Administrative Science Quarterly, 2018.

HUMAN, S. E.; PROVAN, K. G. Legitimacy Building in the Evolution of Small Firm Networks: A Comparative Study of Success and Demise. Administrative Science Quarterly, v. 45, p. 327-365, 2000.

IDREES, I. A.; VASCONCELOS, A. C.; ELLIS, D. Clique and elite: interorganizational knowledge sharing across five star hotels in the Saudi Arabian religious tourism and hospitality industry. Journal of Knowledge Management, 2018.

ISETT, K. R. et al. Networks in public administration scholarship: understanding where we are and where we need to go. Journal of Public Administration Research and Theory, v. 21, n. 1, p. 157173, 2011.

JARILLO, J. C. On strategic networks. Strategic Management Journal, v. 9, n. 1, p. 31-41, 1998

KLEIN, L. L.; PEREIRA, B. A. D. Contribuições para a gestão de redes interorganizacionais: fatores determinantes para a saída de empresas parceiras. Read: Revista Eletrônica de Administração, v. 20, n. 2, p. 305-340, 2014.

KLEIN, L. L.; PEREIRA, B. A. D. The survival of interorganizational networks: a proposal based on resource dependence theory. Revista de Administração Mackenzie, v. 17, n. 4, p. 153-175, 2016.

KNOBEN, J. et al. What do they know? The antecedents of information accuracy differentials in interorganizational networks. Organization Science, v. 2, p. 471-488, 2018.

KOGUT, B. Joint-Ventures: theoretical and empirical perspectives. Strategic Management Journal, v. 9, n. 4, p. 312-332, 1988.

LEWICKI, R.J.; BRINSFIELD C. Measuring trust beliefs and behaviours. In: LYON F; MÖLLERING, G.; SAUNDERS, M. (Eds.). Handbook of research methods on trust. Cheltenham: Edward Elgar, 2011. p. 29-39.

MCGUIRE, M. Collaborative public management: Assessing what we know and how we know it. Public Administration Review, v. 66, n. 1, p. 33-43, 2006.

MILWARD, H. B.; PROVAN, K. G. A manager's guide to choosing and using collaborative networks: IBM center for the business of government. IBM Report on the Business of Government, 2006. 
MOELLER, K. Partner selection, partner behavior, and business network performance: An empirical study on German business networks. Journal of Accounting \& Organizational Change, v. 6, n. 1, p. 27-51, 2010.

OLIVEIRA, W. S. et al. Gestão de Custos Interorganizacionais: uma pesquisa bibliométrica com base em publicações nacionais. RAGC Revista de Auditoria, Governança e Contabilidade, v. 4, n. 16, 2016.

OLSON, M. A lógica da ação coletiva. São Paulo: EDUSP, 1999.

PAQUIN, R. L.; HOWARD-GRENVILLE, J. Blind dates and arranged marriages: Longitudinal processes of network orchestration. Organization Studies, v. 34, n. 11, p. 1623-1653, 2013.

PEREIRA, B. A. D. et al. Desistência da cooperação e encerramento de redes interorganizacionais: em que momento essas abordagens se encontram? RAI - Revista de Administração e Inovação, v. 7, n. 1, p. 62-83, 2010.

PERROW, C. Complex organizations: a critical essay. New York: McGraw-Hill, 1998.

PERRY, M. L.; SENGUPTA, S.; KRAPFEL, R. Effectiveness of horizontal strategic alliances in technologically uncertain environments: are trust and commitment enough? Journal of Business Research, v. 57, p. 951-956, 2004.

PFEFFER, J.; SALANCIK, G. R. The External Control of Organizations: A Resource Dependence Perspective. New York: Harper and Row, 1978.

POPP, J. et al. Inter-organizational networks: A critical review of the literature to inform practice. Washington: IBM's Business of Government center, 2014.

PROVAN, K. G.; HUANG, K. Resource tangibility and the evolution of a publicly funded health and human services network. Public Administration Review, v. 72, n. 3, p. 366-375, 2012.

PROVAN, K.; KENIS, P. Modes of network governance: structure, management and effectiveness. Journal of Public Administration Research and Theory, v. 18, n. 2, p. 229-252, 2008.

PROVAN, K. G.; LEMAIRE, R. H. Core concepts and key ideas for understanding public sector organizational networks: using research to inform scholarship and practice. Public Administration Review, v. 72 , n. 5 , p. $638-648,2012$

PROVAN, K. G.; SYDOW, J. Evaluating Interorganizational Relationships. In: COPPER, S. et al. (Eds.). Handbook of Interorganizational Relations. Oxford: OUP, 2009.

RIBEIRO, F.; COLAUTO R. D. The Relationship Between Board Interlocking and Income Smoothing Practices. Revista Contabilidade \& Finanças, v. 27, n. 70, p. 55-66, 2016.
RICHARDSON, R. J. Pesquisa social: métodos e técnicas. 3. ed. São Paulo: Atlas, 1999.

RING, P. S.; VAN DE VEN, A. H. Developmental processes of cooperative interorganizational relationships. Academy of Management Review, v. 19 , n. 1, p. 90-118, 1994.

ROXENHALL, T. Network structure and network commitment in innovation networks. World Journal of Management, v. 3, n. 1, p. 60-74, 2011.

SADOWSKI, B.; DUYSTERS, G. Strategic technology alliance termination: an empirical investigation. Journal of Engineering and Technology Management, v. 25, p. 305-320, 2008.

SEATON, C. L. et al. Factors that impact the success of interorganizational health promotion collaborations: A scoping review. American Journal of Health Promotion, n. 32, v. 4, p. 1095-1109, 2018

SCHULZ, K.; GEITHNER, S. Between exchange and development: Organizational learning in schools through inter-organizational networks. Learning Organization, v. 17, n. 1, p. 69-85, 2010.

SCHUMPETER, J. A. Theorie der wirtschaftlichenentwicklung. Leipzig: Duncker e Humblot, 1911.

SELLTIZ, C.; WRIGHTSMAN, L. S.; COOK, S. W. Métodos de pesquisa nas relações sociais. São Paulo: Herder, 1972.

SHIPILOV, A. V.; ROWLEY, T. J.; AHARONSON, B. S. When do network matter? A study of tie formation and decay. In: SILVEMAN, D. (Ed.). Ecology and strategy. United Kingdom: Emerald Group, 2006. p. 481-515.

SUCHMAN, M. C. Managing legitimacy: strategic and institutional approaches. Academy of Management Journal, v. 20, n. 3, p. 571 610, 1995.

TUBIN, D.; LEVIN-ROZALIS, M. Interorganizational cooperation: the structural aspect of nurturing trust. International Journal of Public Sector Management, v. 21, n. 7, p. 704-722, 2008.

$\mathrm{XIA}$, J. et al. Alliance formation in the midst of market and network: Insights from resource dependence and network perspectives. Journal of Management, v. 44, n. 5, p. 1899-1925, 2018.

WAARDEN, F. V. Emergence and development of business interest associations: an example from The Netherlands. Organization Studies, v. 13, n. 4, p. 521-561, 1992.

WESTERLUND, M.; RAJALA, R. Learning and innovation in interorganizational network collaboration. Journal of Business \& Industrial Marketing, v. 25, n. 6, p. 435-442, 2010. 
Leander Luiz Klein

ORCID: https://orcid.org/0000-0001-6075-6107

Doutor em Administração pela Universidade Federal de Santa Maria (UFSM); Professor Adjunto na Universidade Federal de Santa Maria (UFSM), Palmeira das Missões - RS, Brasil. E-mail: kleander88@gmail.com

Breno Augusto Diniz Pereira

ORCID: http://orcid.org/0000-0001-7387-5033

Doutor em Administração pela Universidade Federal do Rio Grande do Sul (UFRGS); Professor Adjunto na Universidade Federal de Santa Maria (UFSM), Santa Maria-RS, Brasil. E-mail: brenodpereira@gmail.com 